\title{
Preschoolers' interpretation of doubly quantified sentences
}

\author{
Katalin É. Kiss \\ Research Institute for Linguistics, Hungarian \\ Academy of Sciences, Budapest; \\ Pázmány Péter Catholic University, Piliscsaba \\ ekiss@nytud.hu
}

\section{Mátyás Geröcs}

Research Institute for Linguistics, Hungarian Academy of Sciences, Budapest; Pázmány Péter Catholic University, Piliscsaba mgerocs@gmail.com

Tamás Zétényi

Budapest University of Technology and Economics zetenyi@erg.bme.hu

\begin{abstract}
This paper presents the results of two sentence-picture matching experiments investigating how Hungarian preschoolers interpret doubly quantified sentences involving numerical quantifiers. We claim that for Hungarian children, scope interpretation is primarily determined by the structure of the visual representation of the event associated with the given sentence. We found in a series of previous experiments that children's preferred scope order cannot be derived from either the linear order of quantifiers, or from any other linguistic factor, but seems to be affected by visual cues provided by the picture stimuli. In this follow-up study, we tested two hypotheses, namely: (i) children assign wide scope to the set whose elements are more salient in the visual representation; (ii) children choose the scope interpretation whose visual representation is easier to chunk into identical subevents. The results confirm hypothesis (ii). This converges with the results of former experiments testing children's interpretation of every and each, according to which children use these quantifiers to quantify over events rather than individuals (cf. Philip 1995, etc.).
\end{abstract}

Keywords: acquisition of quantifier scope; scope interpretation; doubly quantified sentences; chunking; quantification over subevents; A-quantification

\section{Introduction}

This paper presents the results of two experiments investigating how Hungarian preschoolers interpret doubly quantified sentences of the type illustrated in (1); what determines their choice between the scope readings represented in (1a) and (1b). 
(1) Three teddy bears are playing with two cars.

a. 'There are three teddy bears, each playing with two cars.' (fig. 1)

b. 'There are two cars, with each of which three teddy bears are playing.' (fig. 2)

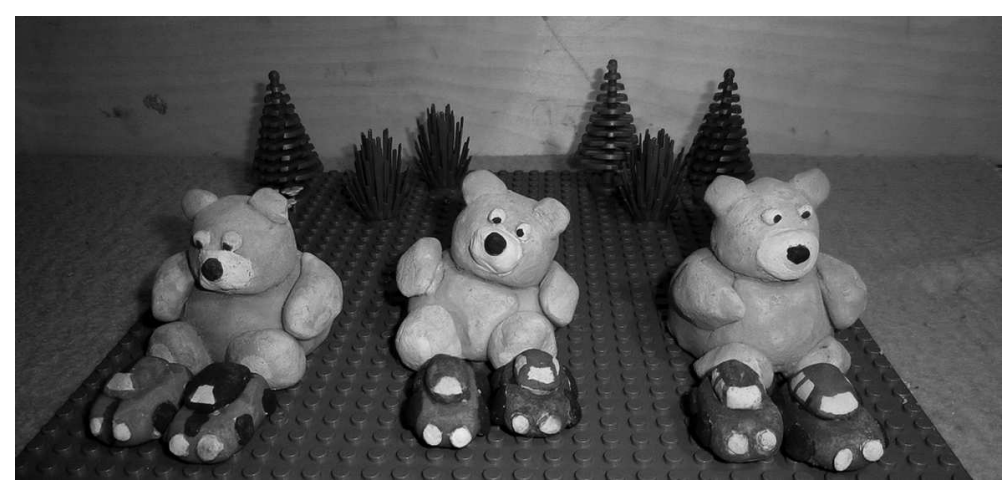

Figure 1

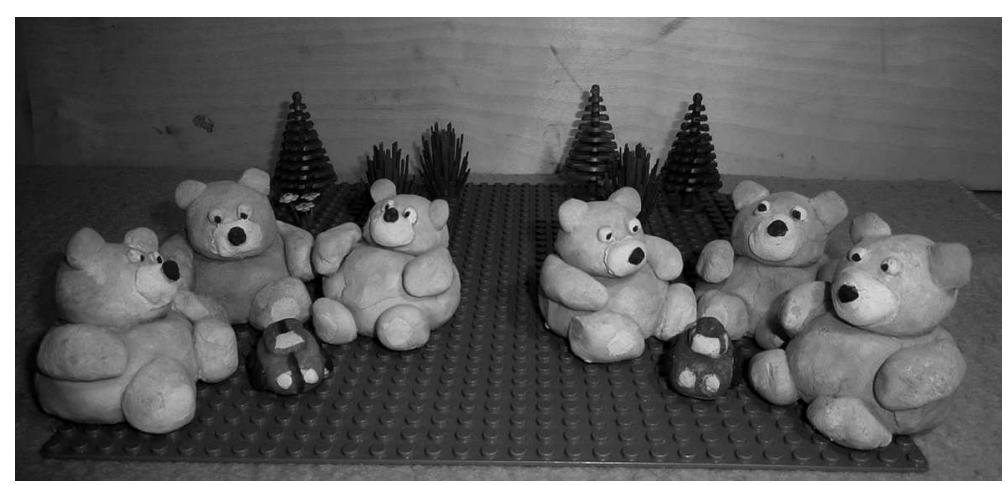

Figure 2

We claim that for Hungarian children, the scope interpretation of a Hungarian doubly quantified sentence is primarily determined by the structure of the visual representation of the event associated with the given sentence. When deciding whether the Hungarian equivalent of (1) describes the picture in figure 1 or that in figure 2, they choose the picture that is easier to segment into identical subevents.

Musolino (1998; etc.) found that English-speaking children tend to assume isomorphism between the linear order and scope order of quantifiers, i.e., they prefer the scope interpretation in (1a). Adults are assumed to derive the inverse scope reading (e.g., that in (1b)) from a virtual (postspellout, or in some frameworks, pre-spellout) syntactic representation. An open question is why children have difficulties in accessing inverse scope 
readings; whether they cannot generate the complex syntactic representations from which inverse scope is derived, or the processing of such sentences is too difficult for them, i.e., whether the problem they have is a problem of competence or performance.

In Hungarian adult grammar, quantifier scope is encoded in surface syntax; quantifiers are overtly raised into scope positions. In the preverbal domain of the sentence, scope order corresponds to linear order; thus the two meanings of (1) are expressed by two sentences of different word orders. The derivation of the syntactic structure of doubly quantified sentences presents no more complications than, e.g., the derivation of wh-questions. Consequently, if children's interpretation of doubly quantified sentences is different from adults' scope reading, the differences are likely to arise because the scope interaction of the two quantifiers is difficult for them to process.

In a series of previous experiments testing Hungarian preschoolers' scope interpretation (É. Kiss \& Geröcs 2012; É. Kiss et al. 2012), we expected even stronger isomorphism between the linear order and the scope order of quantifiers than was attested in the case of English kids, given that Hungarian children receive isomorphic input in adult language. Our results, however, did not support the isomorphism hypothesis. We found that six-year-old Hungarian children can understand scope interaction in doubly quantified sentences, and their scope interpretation is not random but follows a strategy; however, their preferred scope order cannot be derived from either the linear order of quantifiers, or from any other linguistic cue. Our data suggested that it might be affected by visual cues provided by the picture stimuli, i.e., in the case of processing difficulties, children also make use of visual information. Here we present a follow-up study intended to clarify the interaction of linguistic and visual cues in children's scope interpretation. We have tested two hypotheses, namely: (i) children assign wide scope to the set whose elements are more salient/larger in the visual representation; (ii) children choose the scope interpretation whose visual representation is easier to chunk into identical subevents.

The results to be presented confirm hypothesis (ii). They also support and generalize the results of former experiments testing children's interpretation of the universal quantifiers every and each (cf. Philip 1995; Gyuris 1996; Kang 2001; Brooks \& Sekerina 2006), according to which children use these quantifiers to quantify over events rather than individuals.

The paper is organized as follows: section 2 provides the background of the experiments. Section 2.1 summarizes the essentials of the syntax of quantification; section 2.2 discusses former research into the acquisition 
of quantifier scope; and section 2.3 recapitulates our own previous results on how Hungarian children interpret doubly quantified sentences. Section 3 presents in detail two experiments we carried out in order to test what determines children's scope reading in doubly quantified sentences. Section 4 is a discussion of our new results. Section 5 is a conclusion.

\section{Background}

\subsection{The syntax of quantifier scope}

A sentence with two quantifiers such as (2) can have at least three different scope readings, those paraphrased in (2a), (2b), and (2c). (For a recent overview of the literature on quantifier scope, see Szabolcsi 2010.)

(2) Three teddy bears are playing with two cars.

a. 'There are three teddy bears, each of which is playing with two (possibly different) cars.'

b. 'There are two cars, with each of which three (possibly different) teddy bears are playing.'

c. 'There are three teddy bears and two cars, and the former are are playing with the latter.'

Readings (2a) and (2b) are so-called distributive readings. Under reading (2a), where three has wide scope and two has narrow scope, in other words, three has scope over two, the situation involves three teddy bears, and two cars distributed to each of them, i.e., altogether six cars. (More precisely, it involves three teddy bears and up to six cars, given that the two cars assigned to the each of the three teddy bears may partially or fully coincide.) Under reading (2b), where two has wide scope, the situation involves two cars and (up to) six teddy bears. Under reading (2c), where both quantifiers have independent scopes, the situation involves three teddy bears and two cars altogether. The latter meaning is called collective or cumulative depending on whether the whole group of teddy bears is playing with the whole group of cars, or different members of the set of teddy bears are playing with different members of the set of cars. Since this distinction is not relevant from our present perspective, it will be ignored, and reading (2c) will simply be referred to below as 'collective'.

Syntactic theory predicts that a quantifier Q1 has scope over a quantifier Q2 if Q1 c-commands Q2 at some level of representation. (A constituent c-commands its sister constituent and her descendants in the tree 
diagram representing syntactic structure.) In English, the structural representation encoding quantifier scope is often a post-spell-out, virtual structure called Logical Form; at the level of overt syntax, sentences with two or more quantifiers are usually ambiguous. The selection of the preferred interpretation can be affected by various syntactic factors such as the linear order, the grammatical function (e.g., subject versus object status), and the thematic (e.g., agent or patient) role of the quantified constituents. In the case of (2), the most unmarked reading is presumbly that in (2c). The other two readings can be elicited by special, marked means, e.g., by the insertion of a so-called binominal each, expressing distributivity:

(3) Three teddy bears are each playing with two cars.

Pragmatic considerations can also facilitate one reading or the other. Thus, in the case of (4), the distributive reading, whereas in the case of (5), the collective reading is more likely.

(4) Every boy was eating an apple.

(5) Every boy was watching a football game.

In the Hungarian sentence, quantifiers are overtly raised into structural positions where they c-command their scope - cf. Hunyadi (1986); É. Kiss (1987; 1991; 2002; 2010); Szabolcsi (1994; 1997); Brody \& Szabolcsi (2003); Surányi $(2002 ; 2006)$, etc. In the preverbal domain, structural prominence always corresponds to linear precedence, hence if a quantifier Q1 precedes a quantifier Q2, Q1 has scope over Q2. ${ }^{1}$ Thus, Hungarian consistently disambiguates scope; different scope readings are encoded by different sentences. The three interpretations of (2), for example, are expressed by the sentences in (6), (7), and (9). In (6) and (7), the lower quantifier assumes

${ }^{1}$ The isomorphism between the linear order and the scope order of quantifiers is exceptionless in the preverbal domain, and it also holds for most types of ... Q1... Verb... Q2... orders. (The narrow scope of quantifiers in contrastive left dislocation is shown to be illusory by É. Kiss \& Gyuris 2003.) Ambiguity may arise in the case of two postverbal quantifiers, which is a rare sentence pattern, occurring, e.g., as a result of verb movement elicited in questions and in focus constructions:

(i) Miért játszik két maci is három autóval?

why plays two teddy bear three car-with

'Why are two teddy bears playing with three cars?'

For different ways of deriving the occasional inverse scope attested in Q1...V...Q2... and ... V...Q1... Q2... strings, see Brody \& Szabolcsi (2003); Surányi (2002) and É. Kiss (2010). 
scope by being focus-moved to the specifier of the focus projection, whereas the higher quantifier assumes scope by being Q-raised (i.e., left-adjoined) to FocP, as shown in the tree-diagram in (8). Its Q-raising is elicited by the particle $i s$ attached to it. This particle (glossed as DIST), which has various functions in various contexts, assigns quantifier status to a noun phrase supplied with a numerical modifier, and causes it to enter into scope interaction with the other scope-bearing elements of the sentence, i.e., it results in a distributive reading.

(6) Három maci is két autóval játszik.

three teddy bear DIST two car-with plays

'Three teddy bears (each) are playing with two (possibly different) cars.'

(7) Két autóval is három maci játszik.

two car-with DIST three teddy bear plays

'With two cars (each), three (possibly different) teddy bears are playing.'

$(8)$

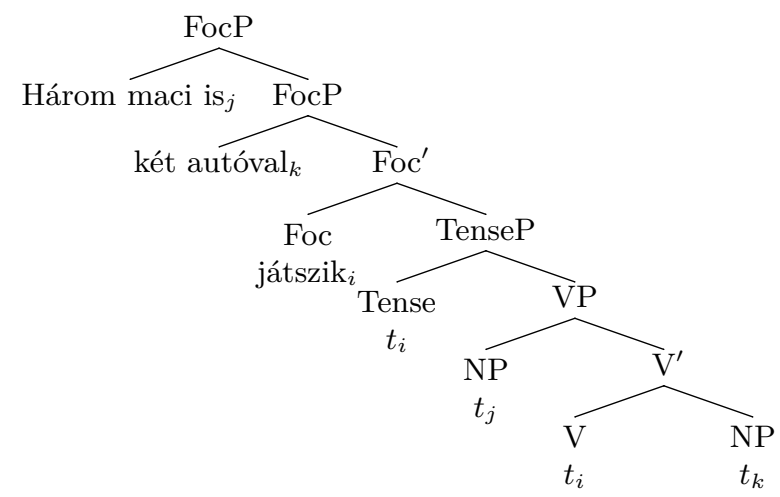

three bear DIST two car-with plays

'Three bears are playing with two cars.'

Notice that három maci is 'three teddy bears DIST' is not in a default subject position either in (6) or in (7) (in fact, the Hungarian sentence contains no designated subject position); it underwent Q-raising in both cases. Though the order in (6) may be more frequent than that in (7), neither structure is syntactically more marked or more complex than the other. $^{2}$

${ }^{2}$ In the preverbal functional domain of the Hungarian sentence, structural positions are associated with logical functions. The subject has no designated structural position; grammatical functions are identified on the basis of morphological case ending (see Pléh 1998; É. Kiss 2002).The SVO and SOV patterns are more frequent 
In sentence (9), displaying the collective reading, the quantified phrases are not in operator positions: the initial expression is in the specifier of the topic projection, and the lower one is in situ, as shown in (10):

(9) Három maci játszik két autóval. ${ }^{3}$

three teddy bear plays two car-with

'A group of three teddy bears is playing with a group of two cars.'

(10)

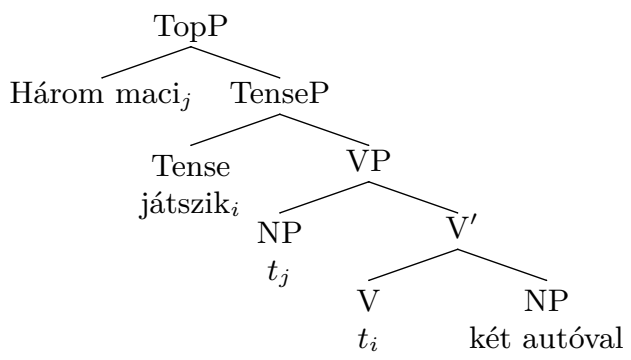

three teddy bear plays two car-with

'Three teddy bears are playing with two cars.'

In (9)-(10) no scope interaction arises because neither of the quantified expressions is supplied with the distributive particle is, and neither of them occupies an operator position.

We tested in an experiment involving 44 students of Budapest University of Technology and Economics whether the interpretation of doubly quantified sentences by adults corresponds to the predictions of Hungarian linguistic literature. The students participating in the experiment listened to sentences (11a) and (11b):

(11) a. Az elöadáson hat sorban is 14 hallgató ült. the talk-at six row-in DIST 14 listener sat

'At the talk, there were 14 listeners sitting in each of six rows.'

than OVS and OSV because the subject is pragmatically the most likely candidate for the topic role, hence the subject is a more common filler of the specifier of the topic projection optionally subsuming the structure in (8) than the object.

${ }^{3}$ The sentence is intended to be pronounced with even stresses. Since it contains no verbal particle, whose relative position indicates focus-induced V-movement, only the lack of stress reduction on the verb shows that the initial expression is a topic occupying Spec,TopP rather than a focus occupying Spec,FocP.

${ }^{4}$ As one of the participants noticed, this sentence does not exclude the possibility of there being further rows with more or less than 14 listeners. This possibility could be excluded by using a universal determiner and a definite article: 
b. Az előadáson 14 hallgató ült hat sorban.

the talk-at 14 listener sat six row-in

'At the talk, there were 14 listeners sitting in six rows.'

The participants were asked after each sentence to answer the question "How many listeners were there?" 40 students answered "84" after the first sentence, and "14" after the second sentence, i.e., $90 \%$ of the subjects gave the predicted answers, thereby confirming the consensual view of Hungarian linguists. Of the remaining four students, three gave the same answer in both cases, one answered " 84 " and two answered " 14 ".

\subsection{Quantifier scope interpretation by preschoolers}

A recurring claim of the literature on children's interpretation of quantifier scope has been that it is primarily determined by c-command in surface syntactic structure. This is predicted to result in isomorphism between linear order and scope order in right-branching languages (see Musolino 1998), and in inverse scope preferences in left-branching languages (see Lidz \& Musolino 2002). Indeed, in the case of sentences involving more than one operator, English-speaking children assign wide scope to the first operator in the majority of cases (Musolino et al. 2000; Musolino 2009). In the case of Kannada, a left-branching language, on the other hand, children prefer inverse scope, i.e., they assign to negation scope over a quantified object in SONegV sentences. For English-speaking adults, inverse scope is claimed to derive from more complex syntactic representations involving post-spellout structure building. English preschoolers can only access inverse scope readings if they receive strong contextual-pragmatic support (Musolino \& Lidz 2006). Children have been claimed not to access certain scope readings either because they lack the means of generating the relevant complex virtual structures, i.e., their grammar is still incomplete (Musolino et al. 2000), or because their parsing abilities/computational resources are still immature (Musolino \& Lidz 2003; Lidz et al. 2004). According to Gennari and MacDonald's alternative theory (2005/2006), children's behavior reflects the distributional patterns of actual language use, which would predict consistent isomorphism for Hungarian children, if scope order and linear order in adult language are, indeed, as isomor-

(i) Az előadáson mind a hat sorban 14 néző ült. the talk-at all the six row-in 14 listener sat 'At the talk, there were 14 listeners in each of the six rows.' 
phic as claimed by the Hungarian linguistic literature and as shown by our experiment testing the interpretation of $(11 \mathrm{a}, \mathrm{b})$.

Studies on the acquisition of quantification in Chinese are particularly relevant from our perspective as Chinese, similarly to Hungarian, also disambiguates quantifier scope to a considerable degree. Both Lee (1997), testing children's interpretation of sentences containing two numerical quantifiers, and Zhou and Crain (2009), testing children's interpretation of sentences involving a universal quantifier and negation, found that children allow more scope readings than adults, i.e., children's grammar allows greater flexibility in the mappings between syntax and semantics than mature grammar.

Studies on the acquisition of universal quantifiers in various languages have shown that children have a non-adult-like understanding of sentences involving the distributive quantifiers every and each (Philip 1995). Children younger than 9-10 years find a sentence like Each flower was in a vase ungrammatical in a situation also involving empty vases - cf. Brooks \& Braine (1996); Gyuris (1996); Brooks \& Sekerina (2006). They tend to judge the sentence Every boy is riding an elephant as false in a situation where there are three boys each riding an elephant and an extra elephant without a boy. This fact is derived by Philip (1995) from the assumption that in child grammar the universal quantifier quantifies over individual events/situations rather individual objects. Children construct subevents from the participants of the original event (from boys and elephants), and they reject this sentence beacuse it is not the case that every subevent involves a boy riding an elephant (Philip 1995; Kang 2001; Brooks \& Sekerina 2006).

\subsection{Quantifier scope interpretation by Hungarian preschoolers - previous research}

The acquisition of quantifier scope interpretation by Hungarian children has been examined by us in previous experiments - see É. Kiss \& Gerőcs (2012), and É. Kiss et al. (2012). We tested how preschoolers aged 4-6 interpret Hungarian doubly quantified sentences of the type illustrated in (6) and (7) above. Our initial hypothesis was that the tendency of identifying scope order with linear order and surface structure prominence attested in the case of English preschoolers (cf. Musolino 1998), i.e., the so-called isomorphism, would be even stronger in the case of Hungarian children, as it is also supported by adult input. This expectation was not confirmed. Truthvalue judgement tasks showed that Hungarian preschoolers can access the 
distributive readings of doubly quantified sentences, e.g., they can associate the doubly quantified sentences in (6) and (7) with the pictures in figures 1 and 2; however, their preferred scope order does not correspond to the linear order/structural prominence of quantifiers. Since scope interpretation by English-speaking adults has been claimed to be affected by the grammatical functions and/or theta roles of the quantified expressions (cf. Ioup 1975; Micham et al. 1980; Fodor 1982; Kurtzman \& MacDonald 1993; Johnson-Laird et al. 1989; Gillen 1991; Tunstall 1998, etc.), we carried out a follow-up study testing the role of these factors, as well.

As reported in É. Kiss et al. (2012), we performed two experiments testing preschoolers' (mean age: 6;5) preferred scope reading in doubly quantified sentences where the relative thematic prominence (agent $>$ patient) or relative functional prominence (subject $>$ object) of the two quantifiers was either identical or opposite to their linear order. The tasks involved truth value judgement, and forced choice between visual representations of different scope interpretations.

One of our experiments tested whether Hungarian preschoolers can access the isomorphic direct scope reading and the non-isomorphic inverse scope reading of doubly quantified sentences in four conditions:

(12) i. subject-initial sentence coupled with a picture showing subject wide scope $(\mathrm{S}>\mathrm{O})$

ii. subject-initial sentence coupled with a picture showing object wide scope $(\mathrm{S}<\mathrm{O})$

iii. object-initial sentence coupled with a picture showing object wide scope $(\mathrm{O}>\mathrm{S})$

iv. object-initial sentence coupled with a picture showing subject wide scope $(\mathrm{O}<\mathrm{S})$

Children were asked if a sentence such as Három maci is két autóval játszik 'Three teddy bears (each) are playing with two cars' is the true description of a picture showing three teddy bears and six cars (figure 1), and/or the true description of a picture showing six teddy bears and two cars (figure 2). The same two pictures were also combined with the sentence Két autóval is három maci játszik "With two cars (each), three teddy bears are playing'. The acceptance rates of the sentence-picture combinations in the four conditions were the following:

(13) Acceptance rates of direct and inverse scope in SOV and OSV

i. $(\mathrm{S}>\mathrm{O}): 91 \%$

iii. $(\mathrm{O}>\mathrm{S}): 67 \%$

ii. $(\mathrm{S}<\mathrm{O}): 63 \%$

iv. $(\mathrm{O}<\mathrm{S}): 41 \%$ 
Whereas the majority of children rejected the non-isomorphic subject wide scope reading in object-initial sentences (condition iv), they unexpectedly accepted the object wide scope reading in subject-initial sentences (condition ii). This result could not be explained by either the isomorphism hypothesis, or the assumption that children favour subject wide scope.

In experiment 2, children listened to eight doubly quantified sentences, each accompanied by two pictures representing its two distributive interpretations. Each pair of pictures was presented twice, coupled with sentences which differed in the relative order of the two preverbal quantifiers. In the eight test sentences, the two quantified expressions represented four different pairs of thematic roles: agent-patient; (inanimate) actor-patient; agent-location; location-patient. The four pairs of quantifiers presented in both linear orders yielded the following eight conditions:
(14) i. Agent, Patient
v. Agent, Location
ii. Patient, Agent
vi. Location, Agent
iii. Actor, Patient
vii. Patient, Location
iv. Patient, Actor
viii. Location, Patient

We were interested in the cases where the majority of children chose the inverse scope reading, i.e., where isomorphism was overruled by thematic prominence (or some other factor). Observe the percentage of inverse scope choices:

(15) Inverse scope preference
i. Agent $<$ Patient: $22 \%$
v. Agent < Location: $20 \%$
ii. Patient < Agent: $42 \%$
vi. Location $<$ Agent: $68 \%$
iii. Actor < Patient: $15 \%$
vii. Patient < Location: $24 \%$
iv. Patient $<$ Actor: $78 \%$
viii. Location < Patient: $78 \%$

Children preferred inverse scope in three cases: in conditions (iv), (vi), and (vii). In cases (iv) and (vi), where children attributed wide scope to the thematically more prominent expression, their choice was not surprising. However, we could not explain the great difference between the inverse scope choices ( $42 \%$ versus $78 \%$ ) in the seemingly similar conditions in (ii) and (iv), represented by Három tornyot is két fiú épit 'Three towers (each), two boys are building', and Három gödröt is két markoló ás 'Three holes (each), two excavators are digging'. Our hypothesis did not predict, either, that in the case of Három esernyö is két széken van rajta 'Three umbrellas are [placed] on two chairs', representing condition (vii), children would 
assign wide scope to the locative argument, which is not more prominent than the patient either positionally, or structurally, or thematically.

Our experiments examined all the linguistic cues that could, in principle, affect children's scope preferences: structural prominence, which coincides with linear precedence in the case of the preverbal quantifiers, thematic prominence, and grammatical functions. None of these cues could fully explain the answers of the children we tested; at the same time, these answers were not accidental but clearly followed a strategy. This fact led us to the conclusion that children's scope preferences might also be affected by visual information; children may decide between two pictures representing two readings of a doubly quantified sentence, e.g., between figure 1 and figure 2, on the basis of some features of the pictures, i.e., on the basis of some visual cue. The follow-up experiments to be presented below test two hypotheses, namely: (i) children assign wide scope to the quantified expression that has larger, more salient denotata in the visual representation, or (ii) children choose the picture that is easier to divide into identical chunks representing identical subevents.

\section{Visual cues affecting children's scope interpretation}

\subsection{Experiment 1}

Experiment 1 aimed to test the hypothesis that children choosing between the visual representations of two distributive readings of a doubly quantified sentence decide on the basis of the relative visual salience of the members of the two sets denoted by the quantified expressions. They assign wide scope to the set whose members are larger in the visual representation.

\subsubsection{Method}

\section{Subjects}

The experiment involved the members of the "big kids' group" in two kindergartens located in districts XII and XXII of Budapest. ${ }^{5}$ The number of subjects participating in the experiment was 27, 12 boys and 15 girls, mean age 6,5 years $(\mathrm{SD}=4$ months $)$. The males' mean age was 6,7 years $(\mathrm{SD}=5$ months $)$, the females' mean age was 6,4 ( $\mathrm{SD}=3$ months).

${ }^{5}$ We owe thanks to Táltos Kindergarten and Halacska Protestant Kindergarten for helping our research in several ways. 


\section{Materials}

The subjects were presented with 16 sentences, each of which was accompanied by a pair of pictures (A5-size, $148 \mathrm{~mm} \times 210 \mathrm{~mm}$ drawings), and they had to decide which of the two pictures the given sentence described. The 16 sentences included 8 test cases and 8 fillers. Each test case involved a doubly quantified sentence associated with two pictures showing its direct and inverse scope readings. We used the test sentences in (16) and (17), presented both in Subject-Object-Verb order (16a, 17a), and in Object-Subject-Verb order (16b, 17b). Every sentence was presented twice, once combined with the picture pair in (i), involving big elements in the set denoted by the initial quantified expression, and small elements in the other set, and another time combined with the picture pair in (ii), involving small elements in the set denoted by the initial quantified expression and big elements in the other set. For example, (16a), the Hungarian equivalent of Two boys are building three towers, was coupled first with a picture pair having big boys and small towers, then with a picture pair having small boys and big towers.

Observe the eight sentence-picture pair combinations we tested. The pair of pictures show the two distributive readings the of the given doubly quantified sentence. In one picture of each pair, the initial quantifier has wide scope; in the other picture, the second quantifier has wide scope. Here the isomorphic picture, showing the direct scope reading of the sentence, is always presented first; however, children saw the direct and inverse scope representations in a varying order.

(16) a. Két fiú is három tornyot épít. two boy DIST three tower-ACC builds

'Two boys (each) are building three towers.'

i.

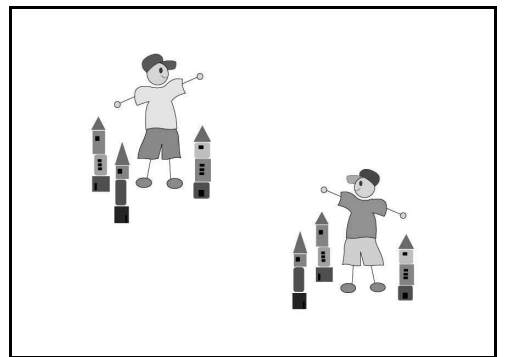

Figure 3a

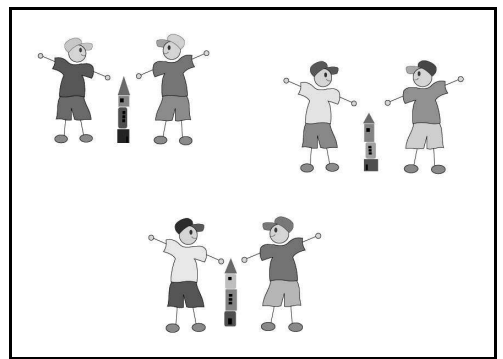

Figure 3b 
ii.

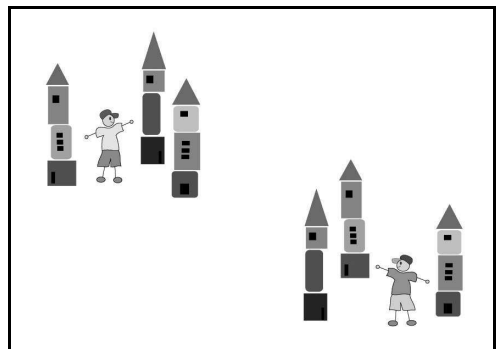

Figure 4a

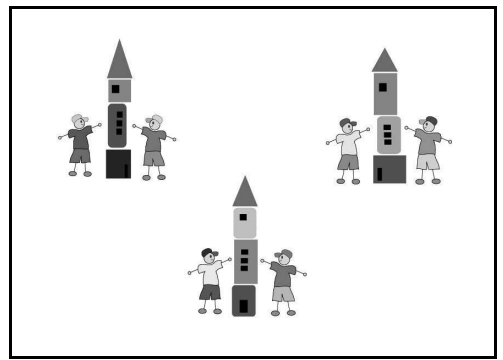

Figure 4b

b. Három tornyot is két fiú épít.

three tower-ACC DIST two boy builds

'Three towers (each) are being built by two boys.'

i.

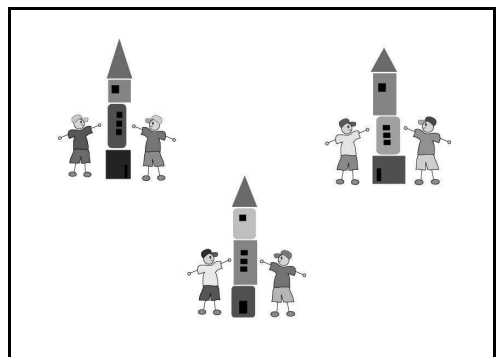

Figure 5a

ii.

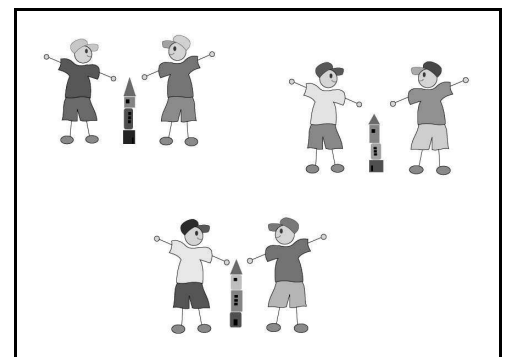

Figure 6a

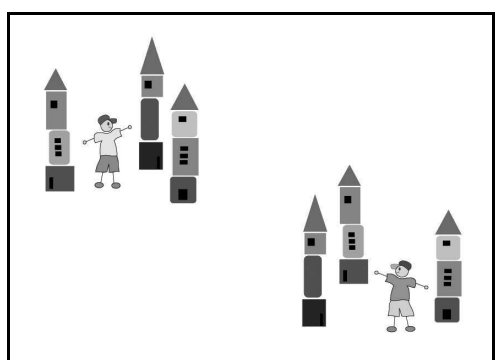

Figure 5b

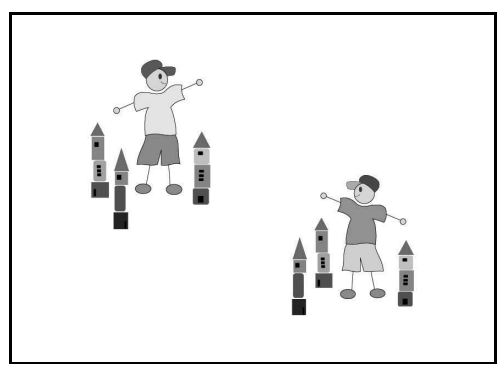

Figure 6b

(17) a. Három lány is két virágot locsol.

three girl DIST two flower-ACC waters

'Three girls (each) are watering three flowers.' 
i.

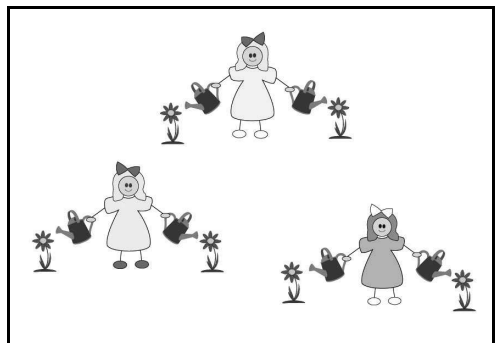

Figure 7a

ii.

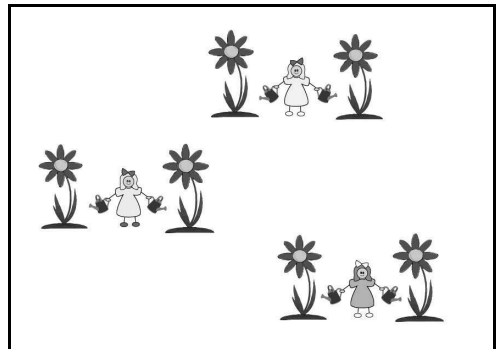

Figure 8a

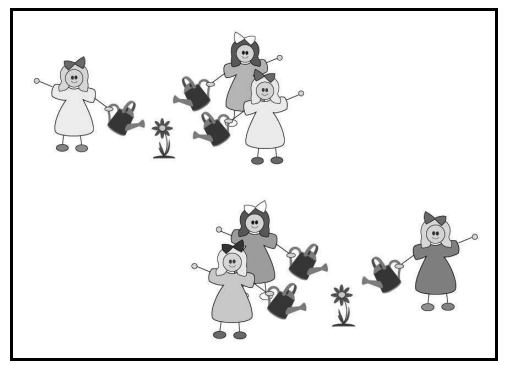

Figure 7b

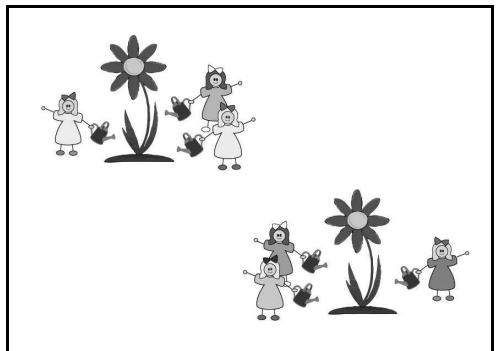

Figure 8b

b. Két virágot is három lány locsol. two flower-ACC DIST three girl waters

'Three flowers (each) are being watered by three girls.'

i.

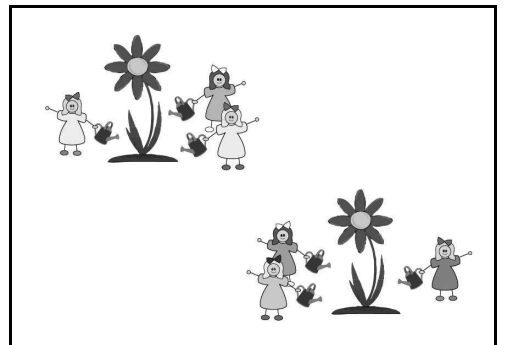

Figure 9a

ii.

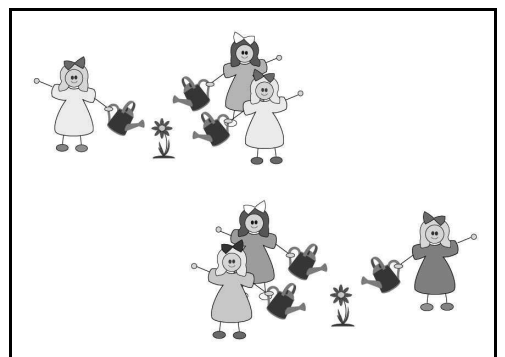

Figure 10a

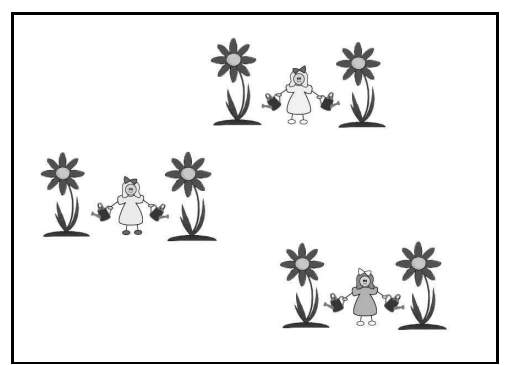

Figure 9b

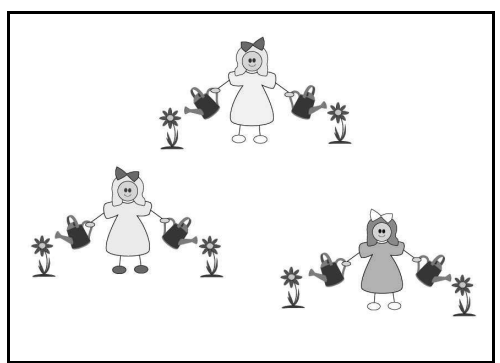

Figure 10b

Acta Linguistica Hungarica 60, 2013 
These sentence-picture pair combinations represent the following four conditions:

\section{Condition 1}

SOV sentence, with the subject set more salient $((16 a)+$ figures 3a,b; (17a) + figures 7a,b)

\section{Condition 2}

SOV sentence, with the object set more salient $((16 a)+$ figures 4a,b; $(17 a)+$ figures 8a,b)

\section{Condition 3}

OSV sentence, with the object set more salient $((16 \mathrm{~b})+$ figures 5a,b; $(17 \mathrm{~b})+$ figures 9a,b)

\section{Condition 4}

OSV sentence, with the subject set more salient $((16 \mathrm{~b})+$ figures $6 \mathrm{a}, \mathrm{b} ;(17 \mathrm{~b})+$ figures 10a,b)

In all four conditions, figure (a) shows the direct scope reading, and figure (b) shows the inverse scope reading of the sentence associated with it. Our hypothesis was that children would choose the direct scope reading in Conditions 1 and 3, where the members of the set denoted by the first quantifier are visually more salient, and they would prefer the inverse scope reading in Conditions 2 and 4, where the members of the set denoted by the second quantifier are visually more salient.

\section{Procedure}

The subject, the experimenter, and a helper were seated at a table in a quiet room of the kindergarten. The helper had a hedgehog puppet on her hand. The experimenter told the child that they were going to play a game. The child and the hedgehog would be shown pairs of pictures. The hedgehog would say what she saw in one of the two pictures, and the child had to find out which of the pictures the hedgehog was talking about.

The child was shown the eight sentence-picture pair combinations listed above, as well as eight distracting sentence-picture pair combinations. The sentence-picture pair combinations were presented in a previously determined random order. The two pictures associated with each sentence were placed on the table side by side. In the test cases, the order of the direct and inverse scope representations was predetermined arbitrarily. The experimenter told the child to look at both pictures carefully. After around five seconds, the hedgehog uttered a sentence (with the helper 
avoiding looking at either of the pictures), and the experimenter asked the child which of the two pictures (s)he thinks the hedgehog spoke about. The child pointed at one of the two pictures, and the experimenter recorded his/her choice on a sheet. After giving the child some positive feedback, the experimenter removed the pictures, and put the next pair on the table.

\subsubsection{Results and discussion}

In the eight sentence-picture pair combinations tested, the direct scope representations (i.e., the "a" figures), and the inverse scope representations (i.e., the "b" figures) were chosen by the subjects in the following proportions:

(16) a. Két fiú is három tornyot épít.

'Two boys are building three towers.'

i. big boys, small towers:

fig. 3a (2 big boys, 6 small towers): $\quad \mathbf{7 8 \%}$

fig. 3 b (6 big boys, 3 small towers): $\quad \mathbf{2 2 \%}$

ii. small boys, big towers:

fig. 4a (2 small boys, 6 big towers): $\quad \mathbf{7 4 \%}$

fig. $4 \mathrm{~b}$ ( 6 small boys, 3 big towers): $\quad \mathbf{2 6 \%}$

b. Három tornyot is két fiú épít.

'Three towers are being built by two boys.'

i. big towers, small boys:

fig. 5a ( 3 big towers, 6 small boys): $\quad \mathbf{3 3 \%}$ fig. $5 \mathrm{~b}$ ( 6 big towers, 2 small boys): $\quad \mathbf{6 7 \%}$

ii. small towers, big boys:

fig. 6a (3 small towers, 6 big boys): $\quad \mathbf{3 0 \%}$

fig. $6 \mathrm{~b}$ ( 6 small towers, 2 big boys): $\quad \mathbf{7 0 \%}$

(17) a. Három lány is két virágot locsol.

'Three girls are watering three flowers.'

i. big girls, small flowers:

fig. 7a (3 big girls, 6 small flowers):

fig. $7 \mathrm{~b}$ ( 6 big girls, 2 small flowers):

ii. small girls, big flowers:

fig. 8 a (3 small girls, 6 big flowers): $\quad \mathbf{7 0 \%}$

fig. 8b (6 small girls, 2 big flowers): $\quad \mathbf{3 0 \%}$

b. Két virágot is három lány locsol.

'Two flowers are being watered by three girls.'

i. big flowers, small girls:

fig. 9a (2 big flowers, 6 small girls): $\quad \mathbf{5 2 \%}$ fig. 9b (6 big flowers, 3 small girls): $\quad \mathbf{4 8 \%}$ 
ii. small flowers, big girls:

fig. 10a (2 small flowers, 6 big girls): $\quad \mathbf{5 2 \%}$

fig. 10b (6 small flowers, 3 big girls): $\quad \mathbf{4 8 \%}$

For each sentence, the picture pairs in (i) and (ii) represent two different conditions: they differ in the relative size of the members of the two sets involved. If visual prominence is relevant for children's scope interpretation, as we hypothesized, then the relative scope of the two quantified expressions should correspond to the relative size of their denotata, i.e., the scope preferences for the picture pairs in (i) and (ii) should be the opposite. That is, for SOV sentences, we predict direct scope preference if the members of the subject set are larger (Condition 1), and inverse scope preference if the members of the object set are larger (Condition 2). For OSV sentences, we predict direct scope preference if the members of the object set are larger (Condition 3), and inverse scope preference if the members of the subject set are larger (Condition 4). That is, we expected the results in Conditions 1 to be the opposite of those in Condition 2, and the results in Conditions 3 to be the opposite of those in Condition 4. These predictions were not borne out: the percentage of the subjects choosing the direct scope representation was nearly or exactly the same both in Conditions 1 and 2, and in Conditions 3 and 4:

(18) Wide scope assignment to the set with visually more salient members

Condition 1: SOV, with the subject set more salient: (16a): $\mathbf{7 8 \%} \quad$ (17a): $\mathbf{6 7 \%}$

Condition 2: SOV, with the object set more salient: $\quad$ (16a): $\mathbf{7 4 \%} \quad$ (17a): $\mathbf{7 0 \%}$

Condition 3: OSV, with the object set more salient: (16b): $\mathbf{3 3 \%} \quad$ (17b): $\mathbf{5 2 \%}$

Condition 4: OSV, with the subject set more salient: (16b): $\mathbf{3 0 \%} \quad$ (17b): $\mathbf{5 2 \%}$

There were no significant differences between answers to picture pairs representing one and the same condition. $\left(\chi_{(\text {Condition } 1)}^{2}=0.00, \mathrm{df}=1, p=\right.$ $1.00 ; \chi_{(\text {Condition } 2)}^{2}=0.24, \mathrm{df}=1, p=0.62 ; \chi_{(\text {Condition } 3)}^{2}=1.21, \mathrm{df}=1$, $p=0.27 ; \chi^{2}$ (Condition 4) $=1.92, \mathrm{df}=1, p=0.17$.)

97-100 percent of the children chose the same scope reading of each sentence both when it was associated with the picture pair in (i), and when it was associated with the picture pair in (ii), irrespective of the fact that the relative sizes of the elements in the two sets were reversed in the two visual representations. The sentences were presented in a random order, and the test sentences were also separated by fillers, i.e., the identity of their preferred scope readings in conditions (i) and (ii) could not be due to a priming effect. This result proves our hypothesis 1 to be wrong; children's scope interpretation of doubly quantified sentences is not affected by the visual prominence of the denotata of the quantified expressions. 


\subsection{Experiment 2}

Experiment 2 aimed to test the hypothesis that when children are shown the visual representations of two distributive scope interpretations of a doubly quantified sentence, they choose the representation that is easier to segment into identical subevents. Results of Philip (1995), Gyuris (1996), Kang (2001), Brooks \& Braine (1996), Brooks \& Sekerina (2006), and others have suggested that children interpret universal quantification as quantification over (sub)events, rather than quantification over individuals. Along this line of reasoning, we assumed that children decompose the original event into subevents in the case of doubly quantified sentences, as well. For them, each member of the set assigned wide scope constitutes a subevent in which it is associated with an instance of the narrow scope set. For example, in the case of (16a) under the subject wide scope reading, represented in figure 3a, the subevents consist of 1 boy +3 towers, whereas under the object wide scope reading, represented in figure $3 \mathrm{~b}$, they consist of 1 tower +2 boys. We hypothesized that children associate with the sentence the visual representation that is easier to chunk into similar subevents.

\subsubsection{Methods}

\section{Subjects}

The experiment involved the members of the "big kids' group" in three kindergartens located in districts VI, XII and XXII of Budapest. ${ }^{6} 38$ subjects participated in the experiment, 18 boys, 20 girls, mean age 6,5 years ( $\mathrm{SD}=4$ months). The males' mean age was 6,6 years $(\mathrm{SD}=5$ months $)$, the females' mean age was $6,5(\mathrm{SD}=3$ months).

\section{Materials}

The children listened to eight doubly quantified sentences, and six filler sentences of various kinds. Each sentence was presented together with a pair of pictures. The two pictures associated with a test sentence showed its direct and inverse scope readings. One member of each picture pair was chunked into identical subevents separated by spaces. In the other picture, the elements (i.e., the members of the two sets denoted by the quantified expressions) were mixed randomly. The child had to point at the picture that (s)he thought the puppet was talking about.

\footnotetext{
${ }^{6}$ We owe thanks to Kincseskert Kindergarten, Táltos Kindergarten, and Halacska
} Protestant Kindergarten for helping our research. 
The sentences and the pairs of pictures associated with them are listed below. In the picture pairs, it is always the isomorphic picture, showing the direct scope reading of the sentence, that is presented first; the inverse scope representation is always second; however, the children saw them in a varying order. In the descriptions of the pictures providing chunked representations, the chunks/subevents are bracketed.

(19) Három tornyot is két fiú épít.

three tower-ACC DIST two boy builds

'Three towers (each) are being built by two boys.'

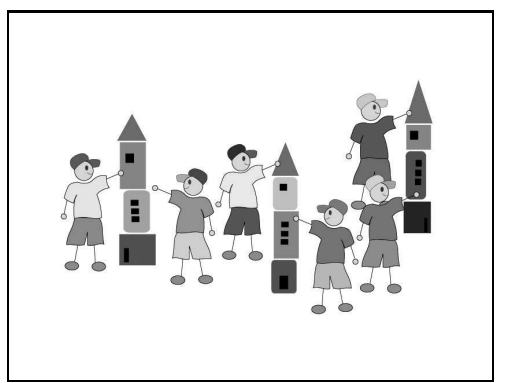

Figure 11a (mixed)

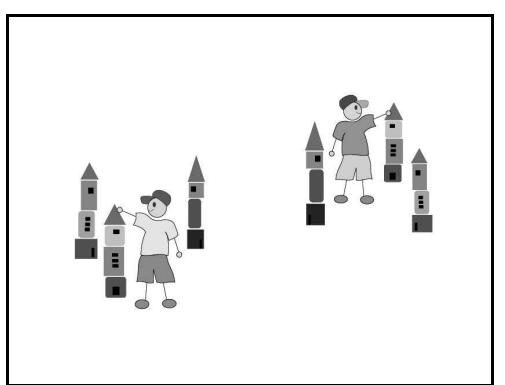

Figure 11b (chunked)

(20) Két markoló is három gödröt ás. two excavator DIST three hole-ACC digs

'Two excavators (each) are digging three holes.'

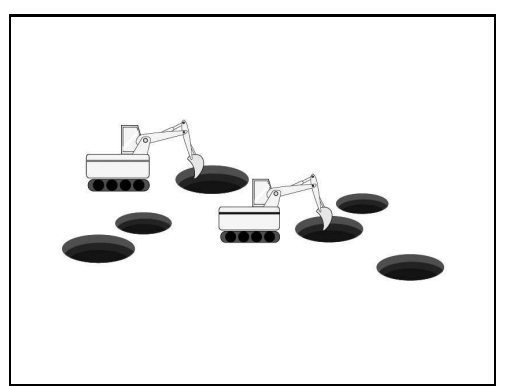

Figure 12a (mixed)

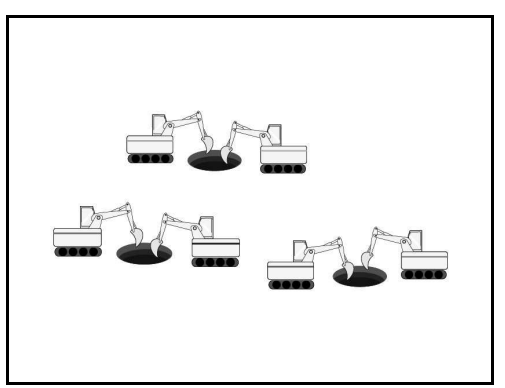

Figure 12b (chunked) 
(21) Két szánkót is három mackó húz. two sled-ACC DIST three teddy-bear pulls

'Two sleds (each) are being pulled by three teddy bears.'

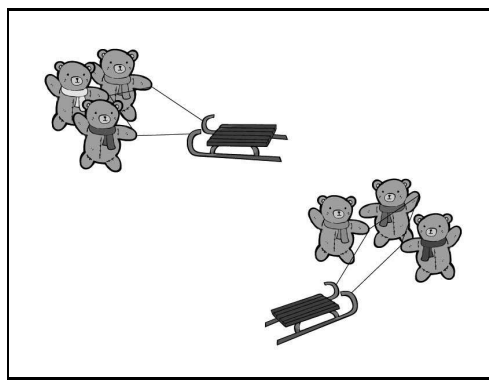

Figure 13a (chunked)

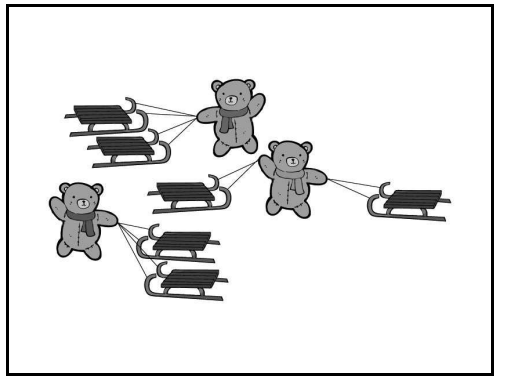

Figure 13b (mixed)

(22) Három lány is két virágot locsol.

three girl DIST two flower-ACC waters

'Three girls (each) are watering two flowers.'

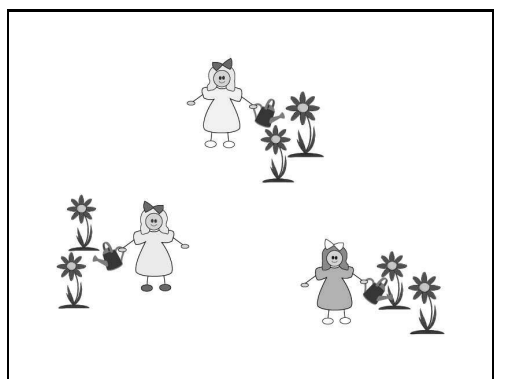

Figure 14a (chunked)

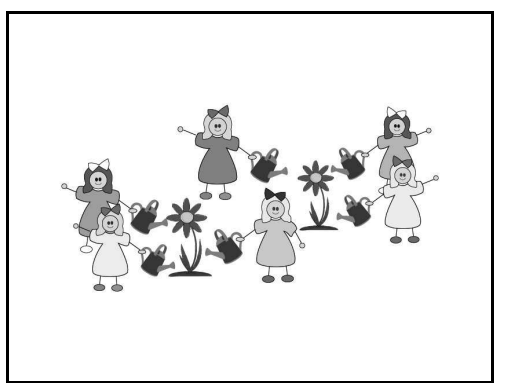

Figure 14b (mixed)

(23) Két fiú is három tornyot épít. two boy DIST three tower-ACC builds

'Two boys (each) are building three towers.'

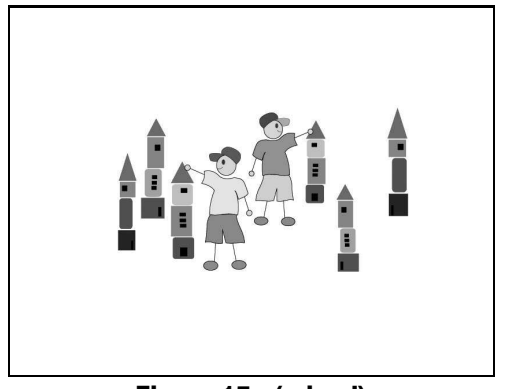

Figure 15a (mixed)

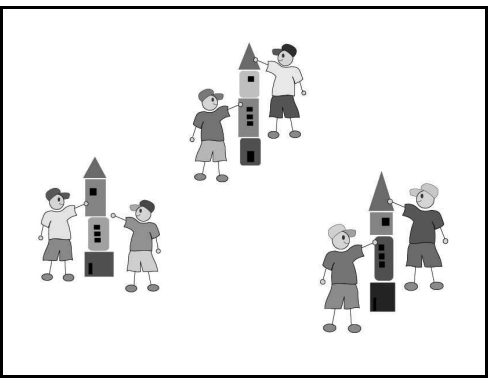

Figure 15b (chunked) 
(24) Három gödröt is két markoló ás. three hole-ACC DIST two excavator digs

'Three holes (each) are being dug by two excavators.'

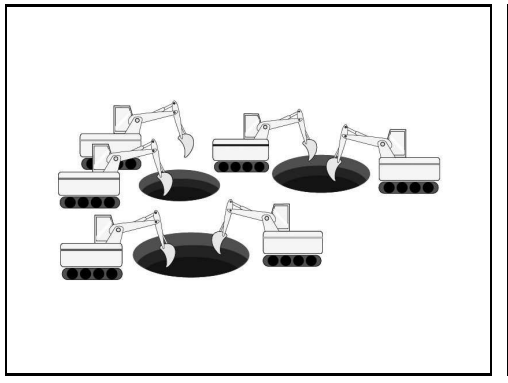

Figure 16a (mixed)

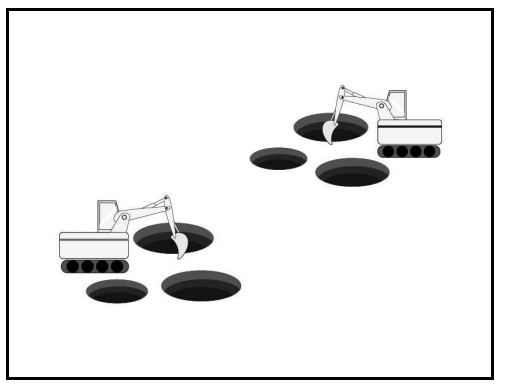

Figure 16b (chunked)

(25) Három mackó is két szánkót húz.

three teddy-bear DIST two sledACC pulls

'Three teddy bears (each) are pulling two sleds.'

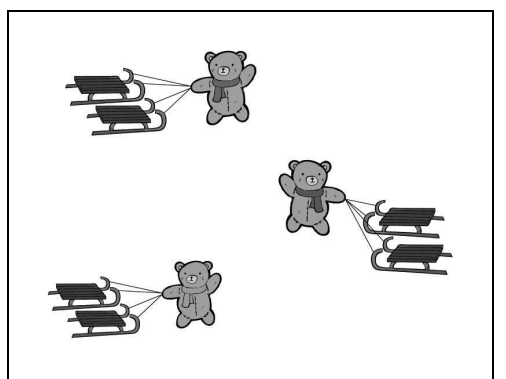

Figure 17a (chunked)

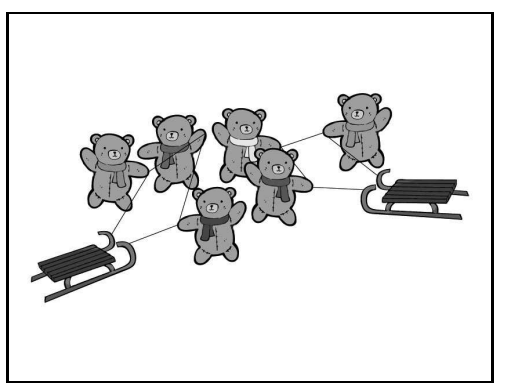

Figure 17b (mixed)

(26) Két virágot is három lány locsol.

two flower-ACC DIST three girl waters

'Two flowers (each) are being watered by three girls.'

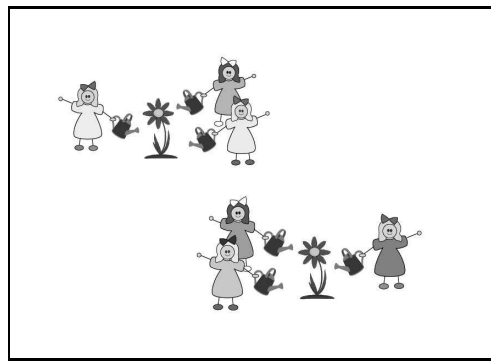

Figure 18a (chunked)

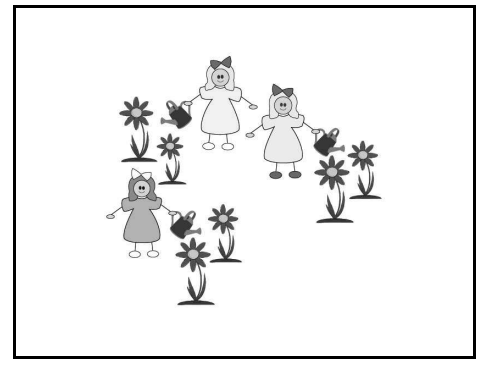

Figure 18b (mixed)

Acta Linguistica Hungarica 60, 2013 
The eight test sentences included four SOV and four OSV sentences. Two sentences of both word order types were coupled with picture pairs where the direct scope representation was chunked, and two were coupled with picture pairs where the inverse scope representation was chunked. That is, the preference for the chunked representation was tested under the following four conditions:

(27) Condition 1

SOV, with the direct scope representation chunked (see (22) and (25))

Condition 2

SOV, with the inverse scope representation chunked ((20) and (23))

Condition 3

OSV, with the direct scope representation chunked ((21) and (26))

Condition 4

OSV, with the inverse scope representation chunked ((19) and (24))

In both the SOV and the OSV types, the set denoted by the subject quantifier is more numerous in one of the examples, and the set denoted by the object quantifier is more numerous in the other example, which controls for the fact that children may tend to assign wide scope to the less numerous quantifier (for economy reasons, so as to chunk the situation into two (rather than three) subevents).

\section{Procedure}

The procedure was the same as in experiment 1 . The child, the experimenter, and a helper were seated at a table in a quiet room of the kindergarten. The helper had a hedgehog puppet on her hand. The experimenter told the child that they were going to play a game. The child and the hedgehog would be shown pairs of pictures. The hedgehog would say what she saw in one of the two pictures, and the child had to find out which of the pictures the hedgehog was talking about.

\subsubsection{Results and discussion}

In the four conditions in (27), the following percentage of subjects opted for the chunked visual representation of the sentences:

(28) Preference for scope reading with a chunked visual representation Cond. 1: SOV, chunked direct scope: ex. (22): $68 \%$; ex. (25): $63 \%$; average: $\mathbf{6 6 \%}$ Cond. 2: SOV, chunked inverse scope: ex. (20): $34 \%$; ex. (23): $24 \%$; average: $\mathbf{2 9 \%}$ Cond. 3: OSV, chunked direct scope: ex. (21): $61 \%$; ex. (26): $55 \%$; average: $\mathbf{5 8 \%}$ Cond. 4: OSV, chunked inverse scope: ex. (19): $66 \%$; ex. (24): 76\%; average: $\mathbf{7 1 \%}$ 
There were no significant differences between answers to picture pairs representing one and the same condition. $\chi^{2}{ }_{(\text {Condition } 1)}=0.06, \mathrm{df}=1, p=$ $0.81 ; \chi_{(\text {Condition } 2)}^{2}=0.16, \mathrm{df}=1, p=0.45 ; \chi^{2}($ Condition 3$)=0.05, \mathrm{df}=1$, $p=0.82 ; \chi^{2}($ Condition 4$)=0.33, \mathrm{df}=1, p=0.56$.)

The majority of children selected the scope reading corresponding to the chunked visual representation in three out of the four conditions. Their choice cannot be derived from linguistic factors. The isomorphism hypothesis, i.e., the assumption that they assigne wide scope to the quantified expression that dominates the other in syntactic structure and precedes it in linear order is contradicted by examples (19) and (24), representing Condition 4, where more than two thirds of children opted for the inverse scope reading. Subject/agent bias is contradicted by examples (21) and (26), representing Condition 3, where the majority of children assigned wide scope to the object. It is not the case, either, that children tend to assign wide scope to the less numerous quantifier; this hypothesis is contradicted by examples (22) and (25). In Conditions 1, 3, and 4, children's preferred scope interpretation is determined by the structure of the visual representations of the scope readings; they chose the interpretation which is visually easier to chunk into distinct identical subevents, confirming our initial hypothesis.

The question arises why this hypothesis appears to be contradicted by examples (20) and (23), representing Condition 2; why children preferred the visual representation that we labelled as mixed in these cases. A possible answer is that visual information interacts with grammatical information, i.e., in sentences where the initial quantifier is subject and agent (and it denotes a less numerous set than the object), the combined effect of linguistic prominence factors counterbalances the effect of the chunked visual representation.

Another possible explanation for the lack of the expected result is that the two pictures associated with sentences (20) and (23) (figures 12a and $12 \mathrm{~b}$, and figures $15 \mathrm{a}$ and $15 \mathrm{~b}$ ) do not differ sufficiently in the relevant respect; both members of these picture pairs can just as easily be chunked into similar subevents. Though the pictures associated by the majority of children with examples (20) and (23) (figures 12a and 15a) were intended by us to be non-segmented, mixed representations, in fact, they, too, can be divided by a single straight line into two identical halves. This explanation allows us to maintain the hypothesis that the primary factor determining children's interpretation of quantifier scope is the structure of the visual representation of the event. Linguistic clues play a secondary role; the majority of subjects assign wide scope to the linguistically more prominent quantifier if both visual representations are segmentable into subevents. 
Our results confirm and extend to non-universal distributive quantification the claim of Philip (1995), Brooks \& Braine (1996), Gyuris (1996), and Brooks \& Sekerina (2006) that universal quantification in child grammar is quantification over events rather than individuals. The claim that child language only quantifies over events correlates in an interesting way with the findings of Bach et al. (1995), who argue that not all languages employ $\mathrm{D}$ (eterminer)-quantifiers quantifying over individuals, but all languages appear to employ some kind(s) of A(dverbial)-quantifiers quantifying over events. The languages that have been shown to use only A-quantifiers include North American indigenous languages such as Mohawk, Navajo, Lakhota, and Straits Salish, Amazonian languages such as Mundurucú (see Pica \& Lecompte 2008), as well as Australian aboriginal languages such as Warlpiri, Mayali, and Gun-djeyhmi (some of which are languages with deficient number systems). If A-quantification is universal and D-quantification is not, it is not unexpected to find A-quantification in the initial toolkit of children, prior to the acquisition of language-specific strategies of D-quantification.

The results of this experiment have shown that children exploit visual resources in the processing of linguistic utterances describing complex situations. Whereas adults hearing a doubly quantified sentence - e.g., those discussed in $(11 \mathrm{a}, \mathrm{b})$ - have no problems in mentally reconstructing the situation presented linguistically, this task appears to be difficult for preschoolers, causing them to make use of the available visual information. (The difficulty of the task was evident in a previous experiment (Experiment 3 reported in É. Kiss et al. 2012), where children had to act out doubly quantified sentences, i.e., they had to realize complex situations solely on the basis of linguistic representations. They opted for the simple, non-distributive, collective interpretation of doubly quantified sentences unless the distributive reading was pragmatically more likely, as in the case of the sentence Két padon is három maci ül 'Three teddy bears are sitting on two benches')

Our finding that the interpretation of a visual stimulus involving a relatively large number of elements is helped if the stimulus is chunked into a smaller number of identical segments is in line with Feigenson and Halberda's (2004) results, who found in experiments with infants that the representation of sets of individuals larger than 3 is facilitated by the spatiotemporal grouping of individuals. 


\section{Conclusion}

Our results presented here have three main implications. First, they contribute in a significant way to the discussion on why children's scope interpretation strategies are different from those of adults. Whereas in child English, the scope order attributed to quantifiers is more isomorphic with the linear order and surface structure hierarchy of quantifiers than in adult English (Musolino 1998; Lidz \& Musolino 2002; Musolino \& Lidz 2003), in child Hungarian it is less isomorphic than in adult Hungarian. The Hungarian data appear to refute the theory of Gennari and MacDonald (2005/2006) that children's scope preferences are determined by the distributional patterns of adult use, and they also contradict the hypothes raised by Musolino et al. (2000) that the syntax of child language is still incomplete, lacking the operations that can derive the complex structures where the surface order and the structural hierarchy of quantifiers is non-isomorphic. In Hungarian grammar, quantified phrases are systematically raised into preverbal scope positions, hence there is clear isomorphism between their linear order, hierarchical order and scope order in the preverbal domain. Isomorphism is attained by a simple "Merge" operation, and there is no indication that it causes any difficulty to children. Isomorphism is grammaticalized; it is not blurred by contextual-pragmatic factors. If a scope reading is pragmatically impossible, the word order isomorphic with it is judged as ungrammatical:

(29) a. ??Mindent falatot mindenki megevett.

every bite-ACC everybody-NOM ate-3SG

b. Mindenki minden falatot megevett.

everybody-NOM every bite-ACC ate-3SG

'Everybody ate every bite.'

Interestingly, adult Chinese is also known to display a strong tendency for isomorphism (see, e.g., Aoun \& Li 1993); nevertheless, Lee (1997) and Zhou \& Crain (2009) have found that Chinese children's scope interpretation is flexible. The converging results of our own experiments and the experiments carried out with Chinese children suggest that children do not interpret doubly quantified sentences differently from adults because the complex syntactic structures supporting some of the readings are not accessible to them. Their difficulties are more likely to be processing difficulties, caused by the set-theoretic operations required by a doubly quantified sentence. This conclusion is more in line with the views of Musolino \& Lidz (2003) and Lidz et al. (2004), who attribute English-speaking children's 
difficulties with inverse scope interpretation to their immature computational resources.

Second, our results have demonstrated that Hungarian children make use of the available visual information, as well, when interpreting sentences involving the scopal interaction of two quantified expressions - as opposed to Hungarian adults, who only use grammatical cues in the interpretion of doubly quantified sentences. Children tend to interpret a visual stimulus contaning a large number of elements by chunking it into a smaller number of similar segments.

Third, the finding that children's interpretation of doubly quantified sentences relies on the chunking of the visual representation of the event into subevents supports the generalization of Philip (1995), Brooks \& Braine (1996), Gyuris (1996), Brooks \& Sekerina (2006), and others that children interpret determiner-type quantifiers as adverbial quantifiers quantifying over events. This property of child language converges with the claim that A-quantification is more universal and more primary than D-quantification (cf. Bach et al. 1995; Pica \& Lecompte 2008).

\section{References}

Aoun, Joseph and Yen-hui Audrey Li. 1993. Syntax of scope. Cambridge MA: MIT Press.

Bach, Emmon, Eloise Jelinek, Angelika Kratzer and Barbara H. Partee (eds.). 1995. Quantification in natural languages. Dordrecht: Kluwer.

Brody, Michael and Anna Szabolcsi. 2003. Overt scope in Hungarian. Syntax 6. 19-51.

Brooks, Patricia J. and Martin D. S. Braine. 1996. What do children know about the universal quantifiers all and each? Cognition 60. 235-268.

Brooks, Patricia J. and Irina A. Sekerina. 2006. Shortcuts to quantifier interpretation in children and adults. Language Acquisition 13. 177-206.

É. Kiss, Katalin. 1987. Configurationality in Hungarian. Dordrecht/Budapest: Reidel/ Akadémiai Kiadó.

É. Kiss, Katalin. 1991. Logical structure in syntactic structure: The case of Hungarian. In J. Huang and R. May (eds.) Logical structure and linguistic structure: Crosslinguistic perspectives. Dordrecht: Kluwer. 111-148.

É. Kiss, Katalin. 2002. The syntax of Hungarian. Cambridge: Cambridge University Press.

É. Kiss, Katalin. 2010. An adjunction analysis of quantifiers and adverbials in the Hungarian sentence. Lingua 120. 506-526.

É. Kiss, Katalin and Mátyás Gerőcs. 2012. How do Hungarian preschoolers interpret doubly quantified sentences? Paper presented at the 2012 Budapest CEU Conference on Cognitive Development. 
É. Kiss, Katalin, Mátyás Gerőcs and Tamás Zétényi. 2012. The linguistic roots of multiplication. Manuscript. Research Institute for Linguistics of the Hungarian Academy of Sciences, Budapest. (http://tinyurl.com/cy8pkgd)

É. Kiss, Katalin and Beáta Gyuris. 2003. Apparent scope inversion under the rise fall contour. Acta Linguistica Hungarica 50. 371-404.

Feigenson, Lisa and Justin Halberda. 2004. Infants chunk object arrays into sets of individuals. Cognition 91. 173-190.

Fodor, Janet. 1982. The mental representation of quantifiers. In S. Peters and E. Saarinen (eds.) Processes, beliefs, and questons. Dordrecht: Reidel. 29-164.

Gennari, Silvia and Maryellen C. MacDonald. 2005/2006. Acquisition of negation and quantification: Insights from adult production and comprehension. Language Acquisition 13. 125-168.

Gillen, Kathryn. 1991. The comprehension of doubly quantified sentences. Doctoral dissertation. University of Durham.

Gyuris, Beáta. 1996. Az univerzális kvantifikáció értelmezése óvodás korban [The interpretation of universal quantification in preschool age]. In G. Székely and E. Cs. Jónás (eds.) Nyelvek és nyelvoktatás a Kárpát-medencében [Languages and language teaching in the Carpathian Basin]. Nyíregyháza: Bessenyei György Könyvkiadó. 290-305.

Hunyadi, László. 1986. The expression of logical scope in Hungarian. On its syntax and semantics. In W. Abraham and S. de Meij (eds.) Topic, focus, and configurationality. Amsterdam \& Philadelphia: John Benjamins. 89-102.

Ioup, Georgette. 1975. Some universals for quantifier scope. In J. P. Kimball (ed.) Syntax and semantics 4. New York: Academic Press. 37-5.

Johnson-Laird, Philip N., Ruth M. J. Byrne and Patrizia Tabossi. 1989. Reasoning by model: The case of multiple quantification. Psychological Review 96. 658-673.

Kang, Hye-Kyung. 2001. Quantifier spreading: Linguistic and pragmatic considerations. Lingua 111. 591-627.

Kurtzman, Howard S. and Maryellen MacDonald. 1993. Resolution of quantifier scope ambiguities. Cognition 48. 273-279.

Lee, Thomas Hun-tak. 1997. Scope and distributivity in child Mandarin. In E. Clark (ed.) Proceedings of the 28th Child Language Research Forum. Stanford, CA: Stanford Linguistics Association, Centre for the Study of Language and Information. 173182.

Lidz, Jeffrey, Erin McMahon, Kristen Syrett, Joshua Viau, Florencia Anggoro, Jessica Peterson-Hicks, Elisa Sneed, Ann Bunger, Taki Flevaris, Anne Graham, Kristy Grohne, Yongeun Lee and John Evar Strid. 2004. Quantifier raising in 4-year-olds. In : A. Brugos, L. Micciulla and Christine E. Smith (eds.) Proceedings of the 28th Boston University Conference on Language Development. Somerville, MA: Cascadilla Press

Lidz, Jeffrey and Julien Musolino. 2002. Children's command of quantification. Cognition 84. 113-154.

Micham, Dennis L., Jack Catlin, Nancy J. VanDerveer and Katherine A. Loveland. 1980. Lexical and structural cues in quantifier scope relations. Journal of Psycholinguistic Research 9. 367-377. 
Musolino, Julien. 1998. Universal grammar and the acquisition of semantic knowledge: An experimental investigation of quantifier-negation interaction in English. Doctoral dissertation. University of Maryland.

Musolino, Julien. 2009. The logical syntax of number words: Theory, acquisition and processing. Cognition 111. 24-45.

Musolino, Julien, Stephen Crain and Rosalind Thornton. 2000. Navigating negative quantificational space. Linguistics 38. 1-32.

Musolino, Julien and Jeffrey Lidz. 2003. The scope of isomorphism: Turning adults into children. Language Acquisition 11. 277-291.

Musolino, Julien and Jeffrey Lidz. 2006. Why children aren't universally successful with quantification. Linguistics 44. 817-852.

Philip, William. 1995. Event quantification in the acquisition of universal quantification. Doctoral dissertation. University of Massachusetts, Amherst.

Pica, Pierre and Alain Lecompte. 2008. Theoretical implications of the study of numbers and numerals in Mundurucu. Philosophical Psychology 21. 507-522.

Pléh, Csaba. 1998. A mondatmegértés a magyar nyelvben [Sentence interpretation in Hungarian]. Budapest: Osiris Kiadó.

Surányi, Balázs. 2002. Multiple operator movements in Hungarian. Doctoral dissertation. LOT, Utrecht.

Surányi, Balázs. 2006. Quantification and focus in negative concord. Lingua 116. 272313.

Szabolcsi, Anna. 1994. All quantifiers are not equal: The case of focus. Acta Linguistica Hungarica 42. 171-187.

Szabolcsi, Anna. 1997. Strategies for scope taking. In A. Szabolcsi (ed.) Ways of scope taking (SLAP 65). Dordrecht: Kluwer. 109-154.

Szabolcsi, Anna. 2010. Quantification. Cambridge: Cambridge University Press.

Tunstall, Susan. 1998. Interpreting quantifiers. Doctoral dissertation. University of Massachusetts, Amherst.

Zhou, Peng and Stephen Crain. 2009. Scope assignment in child language: Evidence from the acquisition of Chinese. Lingua 119. 973-988. 